\title{
A Typical Topology of Boost Converter for Improving Efficiency of Hydraulic Energy Conversion chain
}

\author{
Chirine Benzazah*, Loubna Lazrak and Mustapha Ait Lafkih \\ Laboratory of Automatic, Energy Conversion and Microelectronics (LACEM) \\ Faculty of Sciences and Technology, University of Sultan Moulay Slimane \\ B.P. 523 Beni-Mellal 23000, Morocco \\ ch.benzazah@gmail.com
}

\begin{abstract}
For the efficiency improvement of 7.5MW Hydraulic Energy Conversion System chain (HECS) connected to the distribution grid, a special focus to the conventional two-level converter as well as to the DC-link capacitors balancing control of three-level neutralpoint clamped converter $(3 L-N P C)$ is given to further decrease the cost, power density and stability of the overall system.

In this regards, a design and performance comparison of two AC/DC/AC chains is studied in this paper to select the best topology for a direct driven Multi-Pole Permanent Magnet Synchronous Generator MP-PMSG with a hydraulic turbine in high power operation. One of chains uses the classical two-level Single Input Single Output converter (2L-SISO) and for the voltage balancing across the two capacitors of ( $3 L-N P C)$ converter is achieved using the grid side control, when the other uses a new topology of three-level boost Single Input Dual Output converter (3L-SIDO) and for the DC capacitors voltage unbalance problem of ( $3 L-N P C)$ is realized through the boost converter control.

Simulation results using Matlab-Simulink/SimPower Systems demonstrate the effectiveness and performance of HECS model using a 3L-SIDO converter along with its control strategy method compared with the chain uses the traditional topology of the converter. The results of the new topology illustrate also extremely good dynamic and steady state performance.

The advantage of this research is helping more to find the well advised topology for the hydraulic energy conversion chain with all the design criteria in high power which will be efficacious also in all renewable energy production systems.
\end{abstract}

Keywords: Hydraulic Turbine, Multi Pole-Permanent Magnet Synchronous Generator, Uncontrolled Rectifier, DC/DC Boost Three-Level (3L), DC/DC Boost Two-Level (2L), NPC Inverter, Neutral-Point (NP) Potential Balancing, LCL filter

\section{Introduction}

The power electronic converters are extensive utilized in HECS as an interface between a direct driven MP-PMSG by a hydraulic turbine and the distribution grid [1], [2]. This use amount refers to the ability of these converters to improve the dynamic and static characteristics efficiency of green production system (HECS) [3]. However, in high power, these converters must be selected to be capable to operate in such cited conditions [4], [5]. There are several power converter topologies developed in this energy range [610], the back-to-back (BTB) 3L-NPC converters are most preferable choice [9].

Received (November 14, 2017), Review Result (February 5, 2018), Accepted (February 8, 2018)

* Corresponding Author 
Moreover, to reduce further system complexity, component number and higher control complication, the uncontrolled three phase rectifier AC-DC plus the usual 2L-SISO DC/DC boost converter is more attracted and simple especially for the non-reversible system [11]. But when the power level increases, the inductor of 2L-SISO DC/DC boost converter becomes bulky and costly. In addition, when the required output voltage rises, conduction and switching losses too increases that there aren't devices capable to withstand such stresses for the majorities of cases [12]. To overcome these problems, a new topology using a 3L-SIDO converter can be used for HECS in high power and medium voltage operation. In this paper these two last topologies have been compared to choose the best one of them in order to improve the operation and dynamic of conversion chain (HECS).

\section{Modeling Studied Topologies of Hydraulic Energy Conversion System chain}

\subsection{First Topology with 2L-SISO Boost Converter}

Modeling and description of 2L-SISO boost converter: The first proposed architecture is constituted by a Hydro Power Plant (HPP) type Kaplan, a direct driven permanent magnet synchronous generator PMSG, a Three phase uncontrolled rectifier followed by a DC/DC boost converter type Two-Level Single Input Single Output (2LSISO) and Three-Level Neutral Point Clamped (3L-NPC) inverter (See Figure 1). This is one of the feasible constructions which shows potential for large applications farms [11]. The system can supply an isolated load, a strong electrical grid or the both of them.

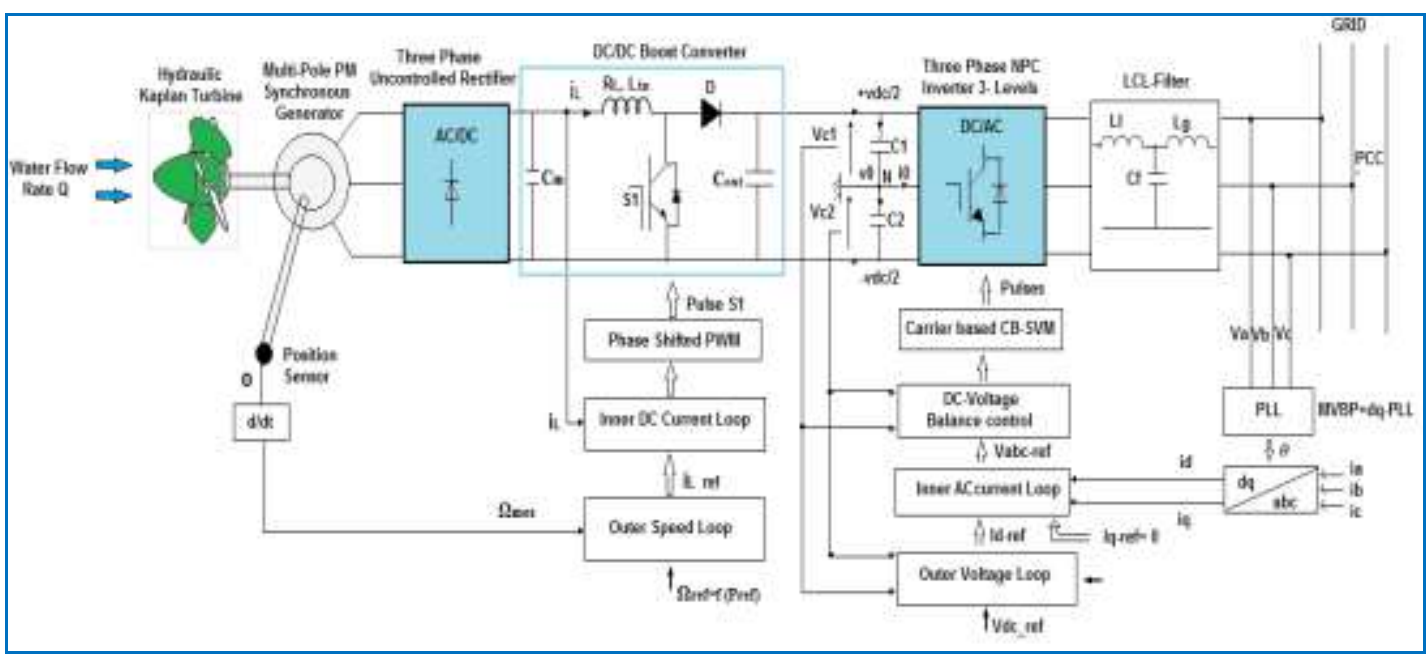

Figure 1. Three-phase Uncontrolled Rectifier plus SISO DC/DC Boost Converter Plus 3L-NPC Inverter Topology Structure

Operation States: The conventional two-level boost converter version shown in Figure 2 can operate in two switching modes as follow:

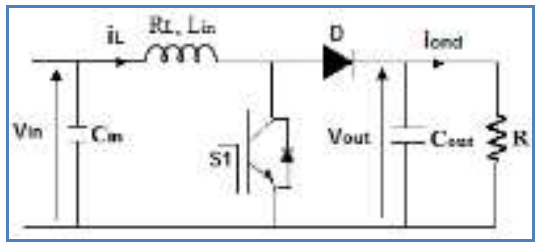

Figure 2. Scheme of SISO Boost Converter 


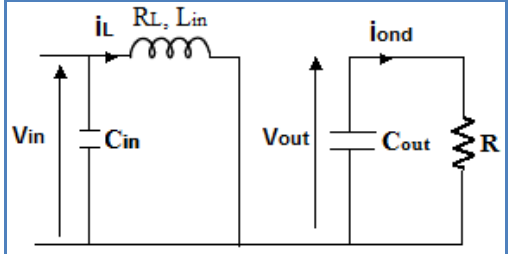

(a)

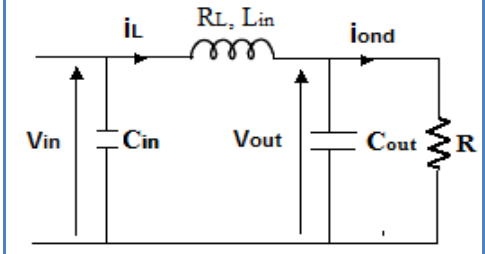

(b)

Figure 3. Equivalent Scheme of SISO Boost Converter: (a) Mode 1 (b) Mode 2

Mode 1: the switch $\mathrm{S} 1$ is $\mathrm{ON}$, implies the inductor current increases and the charge stored in capacitors $\mathrm{C}_{\text {out }}$ supplies current to output as shown in Figure 3.

Mode 2: the switch $\mathrm{S} 1$ is OFF, implies the input delivers energy to capacitors $\mathrm{C}_{\text {out. }}$ The equations (1) and (2) correspond respectively to the mode (1) and (2):

$$
\begin{gathered}
\left\{\begin{array}{c}
L_{\text {in }} \frac{d i_{L}}{d t}=V_{\text {in }}-R_{L} i_{L} \\
C_{\text {out }} \frac{d V_{\text {out }}}{d t}=-i_{\text {ond }}
\end{array}\right. \\
\left\{\begin{array}{c}
L_{\text {in }} \frac{d i_{L}}{d t}=V_{\text {in }}-V_{\text {out }}-R_{L} i_{L} \\
C_{\text {out }} \frac{d V_{\text {out }}}{d t}=i_{L}-i_{\text {ond }}
\end{array}\right.
\end{gathered}
$$

Transfer Function: From the equations (1) and (2), we can deduce the averaging state equations over a switching cycle:

$$
\left\{\begin{array}{c}
L_{\text {in }} \frac{d i_{L}}{d t}=V_{\text {in }}-(1-d) V_{\text {out }}-R_{L} i_{L} \\
C_{\text {out }} \frac{d V_{\text {out }}}{d t}=(1-d) i_{L}-i_{\text {ond }}
\end{array}\right.
$$

With: $d=1$ when $\mathrm{S} 1$ is $\mathrm{ON}$ and $\mathrm{d}=0$ when $\mathrm{S} 1$ is $\mathrm{OFF}$. Introducing perturbation in state variable such that:

$$
\begin{gathered}
i_{L}=I_{L}+\hat{i}_{L} ; v_{\text {in }}=V_{\text {in }}+\hat{v}_{\text {in }} ; d=D+\hat{d} ; i_{\text {ond }}=I_{\text {ond }}+\hat{i}_{\text {ond }} ; v_{\text {out }}=V_{\text {out }}+\hat{v}_{\text {out }} . \\
\left\{\begin{array}{c}
L_{\text {in }} \frac{d\left(I_{L}+\hat{i}_{L}\right)}{d t}=\left(V_{\text {in }}+\hat{v}_{\text {in }}\right)-(1-D-\hat{d})\left(V_{\text {out }}+\hat{v}_{\text {out }}\right)-R_{L}\left(I_{L}+\hat{i}_{L}\right) \\
C_{\text {out }} \frac{d\left(V_{\text {out }}+\hat{v}_{\text {out }}\right)}{d t}=(1-D-\hat{d})\left(I_{L}+\hat{i}_{L}\right)-\left(I_{\text {ond }}+\hat{i}_{\text {ond }}\right)
\end{array}\right.
\end{gathered}
$$

Equate ac and dc quantities then proceed with ac equations by neglect second order ac quantities:

$$
\left\{\begin{array}{c}
L_{\text {in }} \frac{d \hat{i}_{L}}{d t}=\hat{v}_{\text {in }}-(1-D) \hat{v}_{\text {out }}+V_{\text {out }} \hat{d}-R_{L} \hat{i}_{L} \\
C_{\text {out }} \frac{d \hat{v}_{\text {out }}}{d t}=(1-D) \hat{i}_{L}+I_{L} \hat{d}-\hat{i}_{\text {ond }}
\end{array}\right.
$$

Applying Laplace transformation, Matrix small signal model with arranging in symmetrical sequence:

$$
\begin{aligned}
& {\left[\begin{array}{c}
\hat{i}_{L}(s) \\
\hat{v}_{\text {out }}(s)
\end{array}\right]=\left[\begin{array}{cc}
s L_{\text {in }}+R_{L} & 1-D \\
1-D & -s C_{\text {out }}
\end{array}\right]^{-1}\left[\begin{array}{c}
V_{\text {out }} \\
I_{L}
\end{array}\right] \hat{d}(s)++\left[\begin{array}{cc}
s L_{\text {in }}+R_{L} & 1-D \\
1-D & -s C_{\text {out }}
\end{array}\right]^{-1}\left[\begin{array}{c}
1 \\
0
\end{array}\right] \hat{v}_{\text {in }}(s)+} \\
& +\left[\begin{array}{cc}
s L_{\text {in }}+R_{L} & 1-D \\
1-D & -s C_{\text {out }}
\end{array}\right]^{-1}\left[\begin{array}{l}
0 \\
1
\end{array} \text { i }_{\text {ond }}(s)\right.
\end{aligned}
$$

Therefore, the control $\hat{d}(s)$ to input current $\hat{i}_{L}(s)$ transfer function:

$$
H(s)=\frac{\hat{i}_{L}(s)}{\hat{d}(s)}=\frac{C_{\text {out }} V_{\text {out }} s+(1-D) I_{L}}{L_{\text {in }} C_{\text {out }} s^{2}+R_{L} C_{\text {out }} s+(1-D)^{2}}
$$


Proposed Control Strategy: The control algorithm of the hydraulic energy conversion system is applied to extract the full power output from hydraulic turbine. Detailed modeling and control strategy of the first system comprising an uncontrolled rectifier plus 2L-SISO DC/DC boost converter followed by a 3L-NPC inverter have been studied in our previous works [11], [13].

This control strategy can be divided in two parts: the generator side 2L-SISO boost converter and the grid side 3L-NPC converter. The generator side 2L-SIDO boost converter is principally used to control inductor current in the 2L-SISO boost converter in order to extract the full energy from the turbine. The grid side 3L-NPC converter is mainly used to keep the voltage in the DC-link capacitor constant, to control the active/reactive power delivered to the grid and also to adjust the neutral-point voltage deviation for resolving the DC capacitors voltage unbalance problem of $3 \mathrm{~L}-\mathrm{NPC}$ inverter that leads to system instability.

\subsection{Second Topology with 3L-SIDO DC/DC Boost Converter}

The second topology architecture to be compared is the same as above except that the type of DC/DC boost converter 2L-SISO is replaced by another based on a three-level Single Input Dual Output (3L-SIDO) and the first capacitance stage has been eliminated since the two capacitors that represent the input source of the 3-level inverter are also the output of the 2-level boost converter. Also the control mode of this new topology has been changed to improve significantly the efficiency, the converter power density and thus the cost. (See Figure 4)

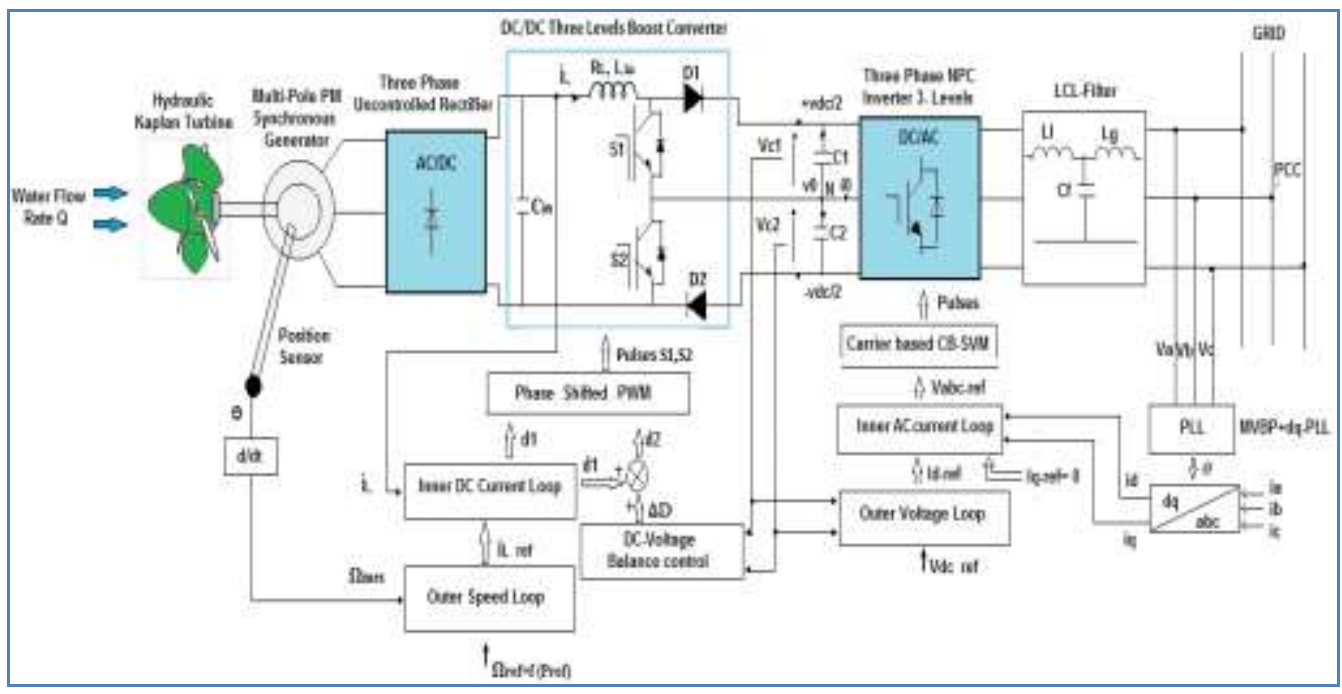
Figure 4. Three-phase Uncontrolled Rectifier Plus SIDO DC/DC BOOST
CONVERTER PLUS 3L-NPC Inverter Topology Structure

Modeling and Description of 3L-SIDO Boost Converter: Different to the conventional single switch converter, the Single Input Dual Output SIDO Boost converter has two capacitors and one inductor. Here the two switches are independent; the duty cycles are defined separately as $\mathrm{d}_{1}$ and $\mathrm{d}_{2}$.

Operation states: The three-level boost converter SIDO has four operation modes which are depended on the states of switches. The operating states of the converter are shown in Figure 5. 


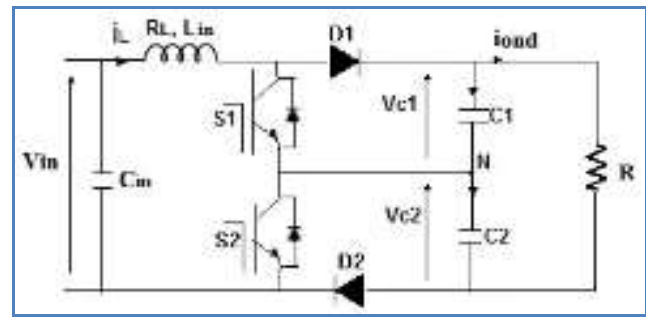

Figure 5. Scheme of SIDO Boost Converter

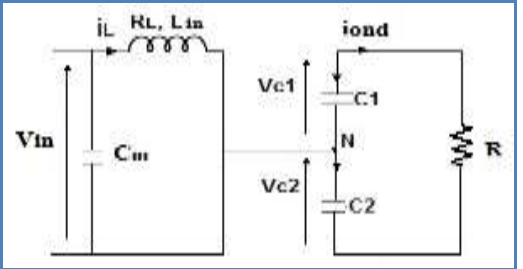

(a)

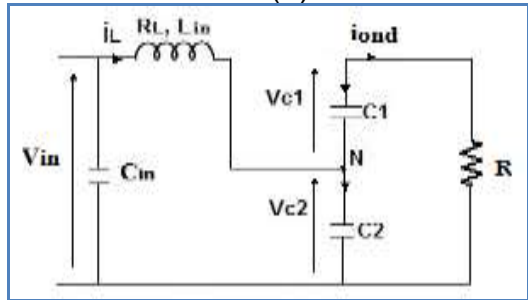

(c)

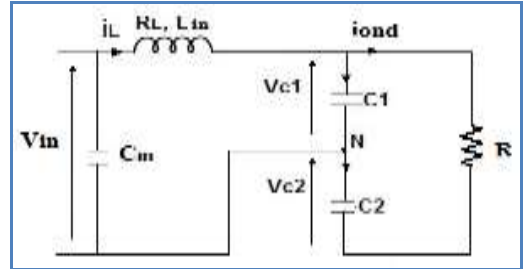

(b)

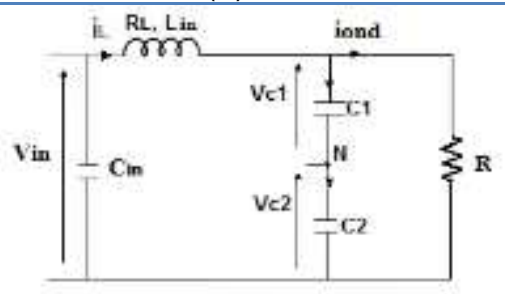

(d)

Figure 6. Equivalent Scheme of DC/DC Boost Converter: (a) Mode 1 (b) Mode 2 (c) Mode 3 (d) Mode 4

Mode 1: is the mode of inductor charging $(\mathrm{S} 1=\mathrm{S} 2=1)$, relates at the time when switches $\mathrm{S} 1$ and S2 are ON (Figure 6a). Through these states the inductor is being charged from the source and the load is supplied from the energy stocked in the capacitors $(\mathrm{C} 1, \mathrm{C} 2)$ over the earlier cycle.

Mode 2: is the mode of capacitor charging $\mathrm{C} 1(\mathrm{~S} 1=0 ; \mathrm{S} 2=1)$, relates at the time when switches $\mathrm{S} 1$ is OFF and S2 is ON (Figure 6b). Through these states, energy is being transported from the inductor to capacitor $\mathrm{C} 1$ and the load is supplied from the source and the inductor.

Mode 3: is the mode of capacitor charging C2 $(\mathrm{S} 1=1 ; \mathrm{S} 2=0)$, relates at the time when switches S1 is ON and S2 is OFF (Figure 6c). Through these states, energy is being transported from the inductor to capacitor $\mathrm{C} 2$ and the load is supplied from the source and the inductor.

Mode 4: is the mode of capacitors $\mathrm{C} 1$ and $\mathrm{C} 2$ charging $(\mathrm{S} 1=\mathrm{S} 2=0)$, relates at the time when switches S1 and S2 are OFF (Figure 6d). Through these states, energy is being transported from the inductor to the capacitors $(\mathrm{C} 1, \mathrm{C} 2)$.

For the 3L-SIDO Boost converter equations modeling, the PMSG plus the uncontrolled three phase rectifier is illustrated by an input voltage Vin and the grid side converter along with LCL filter is illustrated by a resistance load $\mathrm{R}$ as demonstrated in Figure 5.

The state equations relating to the mode 1 , mode 2 , mode 3 and mode 4 are described in (8), (9), (10) and (11) respectively.

$$
\left\{\begin{array} { c } 
{ L _ { i n } \frac { d i _ { L } } { d t } = V _ { i n } } \\
{ C _ { 1 } \frac { d V _ { C 1 } } { d t } = - \frac { V _ { C 1 } + V _ { C 2 } } { R } } \\
{ C _ { 2 } \frac { d V _ { C 2 } } { d t } = - \frac { V _ { C 1 } + V _ { C 2 } } { R } }
\end{array} \quad ( 8 ) \left\{\begin{array}{c}
L_{i n} \frac{d i_{L}}{d t}=V_{i n}-V_{C 1} \\
C_{1} \frac{d V_{C 1}}{d t}=i_{L}-\frac{V_{C 1}+V_{C 2}}{R} \\
C_{2} \frac{d V_{C 2}}{d t}=-\frac{V_{C 1}+V_{C 2}}{R}
\end{array}\right.\right.
$$




$$
\left\{\begin{array} { c } 
{ L _ { i n } \frac { d i _ { L } } { d t } = V _ { i n } - V _ { C 2 } } \\
{ C _ { 1 } \frac { d V _ { C 1 } } { d t } = - \frac { V _ { C 1 } + V _ { C 2 } } { R } ( 1 0 ) } \\
{ C _ { 2 } \frac { d V _ { C 2 } } { d t } = i _ { L } - \frac { V _ { C 1 } + V _ { C 2 } } { R } }
\end{array} \quad \left\{\begin{array}{c}
L_{i n} \frac{d i_{L}}{d t}=V_{i n}-V_{C 1}-V_{C 2} \\
C_{1} \frac{d V_{C 1}}{d t}=i_{L}-\frac{V_{C 1}+V_{C 2}}{R} \\
C_{2} \frac{d V_{C 2}}{d t}=i_{L}-\frac{V_{C 1}+V_{C 2}}{R}
\end{array}\right.\right.
$$

Where $\mathrm{V}_{\text {in }}$ is the input voltage, $\mathrm{V}_{\mathrm{C} 1}, \mathrm{~V}_{\mathrm{C} 2}$ represent the corresponding voltages in $\mathrm{C} 1$ and $\mathrm{C} 2, \mathrm{i}_{\mathrm{L}}$ is the inductor current and $\mathrm{R}$ is the load resistor.

Transfer function: From the equations (8) until (11), we can deduce the averaging state equations over a switching cycle:

$$
\left\{\begin{array}{c}
L_{i n} \frac{d i_{L}}{d t}=V_{i n}-\left(1-d_{1}\right) V_{C 1}-\left(1-d_{2}\right) V_{C 2} \\
C_{1} \frac{d V_{C 1}}{d t}=\left(1-d_{1}\right) i_{L}-\frac{V_{C 1}+V_{C 2}}{R} \\
C_{2} \frac{d V_{C 2}}{d t}=\left(1-d_{2}\right) i_{L}-\frac{V_{C 1}+V_{C 2}}{R}
\end{array}\right.
$$

With: $\mathrm{d}_{1}=\mathrm{d}_{2}=1$ when $(\mathrm{S} 1 ; \mathrm{S} 2)$ are respectively $\mathrm{ON}$ and $\mathrm{d}_{1}=\mathrm{d}_{2}==0$ when $(\mathrm{S} 1 ; \mathrm{S} 2)$ are respectively $\mathrm{OFF}$.

Introducing perturbation in state variable such that:

$i_{L}=I_{L}+\hat{i}_{L} ; v_{i n}=V_{i n}+\hat{v}_{i n} ; d_{1}=D_{1}+\hat{d}_{1} ; d_{2}=D_{2}+\hat{d}_{2} ; v_{c 1}=V_{c 1}+\hat{v}_{c 1} ; v_{c 2}=V_{c 2}+\hat{v}_{c 2}$

Then equate ac and dc quantities then proceed with ac equations by neglect second order ac quantities:

$$
\begin{gathered}
\left\{\begin{array}{c}
L_{i n} \frac{d \hat{i}_{L}}{d t}=\hat{v}_{i n}-\left(1-D_{1}\right) \hat{v}_{C 1}-\left(1-D_{2}\right) \hat{v}_{C 2}+V_{C 1} \hat{d}_{1}+V_{C 2} \hat{d}_{2} \\
C_{1} \frac{d \hat{v}_{C 1}}{d t}=\left(1-D_{1}\right) \hat{i}_{L}-I_{L} \hat{d}_{1}-\frac{\hat{v}_{C 1}}{R}-\frac{\hat{v}_{C 2}}{R} \\
C_{2} \frac{d \hat{v}_{C 2}}{d t}=\left(1-D_{2}\right) \hat{i}_{L}-I_{L} \hat{d}_{2}-\frac{\hat{v}_{C 1}}{R}-\frac{\hat{v}_{C 2}}{R}
\end{array}\right. \\
\left\{\begin{array}{c}
\frac{d \hat{d}_{L}}{d t}=\frac{1}{L_{i n}} \hat{v}_{i n}-\frac{\left(1-D_{1}\right)}{L_{i n}} \hat{v}_{C 1}-\frac{\left(1-D_{2}\right)}{L_{i n}} \hat{v}_{C 2}+\frac{V_{C 1}}{L_{i n}} \hat{d}_{1}+\frac{V_{C 2}}{L_{i n}} \hat{d}_{2} \\
\frac{d \hat{v}_{C 1}}{d t}=\frac{\left(1-D_{1}\right)}{C_{1}} \hat{i}_{L}-\frac{I_{L}}{C_{1}} \hat{d}_{1}-\frac{1}{R C_{1}} \hat{v}_{C 1}-\frac{1}{R C_{1}} \hat{v}_{C 2} \\
\frac{d \hat{v}_{C 2}}{d t}=\frac{\left(1-D_{2}\right)}{C_{2}} \hat{i}_{L}-\frac{I_{L}}{C_{2}} \hat{d}_{2}-\frac{1}{R C_{2}} \hat{v}_{C 1}-\frac{1}{R C_{2}} \hat{v}_{C 2}
\end{array}\right.
\end{gathered}
$$

Applying Laplace transformation, Matrix small signal model with arranging in symmetrical sequence:

$$
\begin{gathered}
{\left[\begin{array}{c}
\hat{i}_{L}(s) \\
\hat{v}_{C 1}(s) \\
\hat{v}_{C 2}(s)
\end{array}\right]=\left[\begin{array}{ccc}
s & \frac{1-D_{1}}{L_{i n}} & \frac{1-D_{2}}{L_{i n}} \\
\frac{1-D_{1}}{C_{1}} & -\left(s+\frac{1}{R C_{1}}\right) & -\frac{1}{R C_{1}} \\
\frac{1-D_{2}}{C_{2}} & -\frac{1}{R C_{2}} & -\left(s+\frac{1}{R C_{2}}\right)
\end{array}\right]^{-1}\left[\begin{array}{c}
\frac{1}{L_{i n}} \\
0 \\
0
\end{array}\right] \hat{v}_{i n}(s)+\left[\begin{array}{c}
\frac{V_{C 1}}{L_{i n}} \\
\frac{I_{L}}{C_{1}} \\
0
\end{array}\right] \hat{d}_{1}(s)+\left[\begin{array}{c}
\frac{V_{C 2}}{L_{i n}} \\
0 \\
\frac{I_{L}}{C_{2}}
\end{array}\right] \hat{d}_{2}(s)} \\
{\left[\begin{array}{c}
\hat{i}_{L}(s) \\
\hat{v}_{C 1}(s) \\
\hat{v}_{C 2}(s)
\end{array}\right]=\left[\begin{array}{ccc}
s & \frac{1-D_{1}}{L_{i n}} & \frac{1-D_{2}}{L_{i n}} \\
\frac{1-D_{1}}{C_{1}} & -\left(s+\frac{1}{R C_{1}}\right) & -\frac{1}{R C_{1}} \\
\frac{1-D_{2}}{C_{2}} & -\frac{1}{R C_{2}} & -\left(s+\frac{1}{R C_{2}}\right)
\end{array}\right]^{-1}\left[\begin{array}{ccc}
\frac{1}{L_{i n}} & \frac{V_{C 1}}{L_{i n}} & \frac{V_{C 2}}{L_{i n}} \\
0 & \frac{I_{L}}{C_{1}} & 0 \\
0 & 0 & \frac{I_{L}}{C_{2}}
\end{array}\right]\left[\begin{array}{c}
\hat{v}_{i n}(s) \\
\hat{d}_{1}(s) \\
\hat{d}_{2}(s)
\end{array}\right]}
\end{gathered}
$$

Where $\mathrm{D}_{1}$ is the steady state value of duty cycle $\hat{d}_{1}$ and $\mathrm{D}_{2}$ is the steady state value of duty cycle $\hat{d}_{2}$.

To comprehend well the link, we express the average of two duty cycles as $\hat{d}: \hat{d}=\frac{\hat{d}_{1}+\hat{d}_{2}}{2}$ 
The error of the two duty cycle as $\Delta \hat{d}$ yields: $\Delta \hat{d}=\hat{d}_{2}-\hat{d}_{1}$

By introducing the two states variables $\hat{d}$ and $\Delta \hat{d}$, the matrix small signal model

$$
\left[\begin{array}{c}
\hat{i}_{L}(s) \\
\hat{v}_{C 1}(s) \\
\hat{v}_{C 2}(s)
\end{array}\right]=\left[\begin{array}{ccc}
s & \frac{1-D_{1}}{L_{i n}} & \frac{1-D_{2}}{L_{i n}} \\
\frac{1-D_{1}}{C_{1}} & -\left(s+\frac{1}{R C_{1}}\right) & -\frac{1}{R C_{1}} \\
\frac{1-D_{2}}{C_{2}} & -\frac{1}{R C_{2}} & -\left(s+\frac{1}{R C_{2}}\right)
\end{array}\right]^{-1}\left[\begin{array}{ccc}
\frac{1}{L_{i n}} & \frac{V_{C 1}}{L_{i n}} & \frac{V_{C 2}}{L_{i n}} \\
0 & \frac{I_{L}}{C_{1}} & 0 \\
0 & 0 & \frac{I_{L}}{C_{2}}
\end{array}\right]\left[\begin{array}{ccc}
1 & 0 & 0 \\
0 & 1 & -\frac{1}{2} \\
0 & 1 & \frac{1}{2}
\end{array}\right]\left[\begin{array}{c}
\hat{v}_{i n}(s) \\
\hat{d}(s) \\
\Delta \hat{d}(s)
\end{array}\right]
$$

becomes:

After the transformation, we finally get the matrix small signal model:

$$
\left[\begin{array}{c}
\hat{i}_{L}(s) \\
\hat{v}_{C 1}(s) \\
\hat{v}_{C 2}(s)
\end{array}\right]=[A]^{-1}\left[\begin{array}{ccc}
\frac{1}{L_{i n}} & \frac{V_{C 1}+V_{C 2}}{L_{i n}} & \frac{V_{C 2}-V_{C 1}}{2 L_{i n}} \\
0 & \frac{I_{L}}{C_{1}} & -\frac{I_{L}}{2 C_{1}} \\
0 & \frac{I_{L}}{C_{2}} & \frac{I_{L}}{2 C_{2}}
\end{array}\right]\left[\begin{array}{c}
\hat{v}_{i n}(s) \\
\hat{d}(s) \\
\Delta \hat{d}(s)
\end{array}\right] \text { Where: } \quad[A]=\left[\begin{array}{ccc}
s & \frac{1-D_{1}}{L_{i n}} & \frac{1-D_{2}}{L_{i n}} \\
\frac{1-D_{1}}{C_{1}} & -\left(s+\frac{1}{R C_{1}}\right) & -\frac{1}{R C_{1}} \\
\frac{1-D_{2}}{C_{2}} & -\frac{1}{R C_{2}} & -\left(s+\frac{1}{R C_{2}}\right)
\end{array}\right]
$$

For the simplification, we adopted $\mathrm{D}_{1}=\mathrm{D}_{2}=\mathrm{D}$ :

$$
\left[\begin{array}{c}
\hat{i}_{L}(s) \\
\hat{v}_{C 1}(s) \\
\hat{v}_{C 2}(s)
\end{array}\right]=\frac{1}{\operatorname{det}(A)}\left[\begin{array}{ccc}
s^{2}+\frac{1}{R} \frac{C_{1}+C_{2}}{C_{1} C_{2}} s & \frac{1-D}{L_{i n}} s & \frac{1-D}{L_{i n}} s \\
\frac{1-D}{C_{1}} s & -s\left(s+\frac{1}{R C_{2}}\right)-\frac{(1-D)^{2}}{L_{i n} C_{2}} & \frac{1}{R C_{1}} s+\frac{(1-D)^{2}}{L_{i n} C_{1}} \\
\frac{1-D}{C_{2}} s & \frac{1}{R C_{2}} s+\frac{(1-D)^{2}}{L_{i n} C_{2}} & -s\left(s+\frac{1}{R C_{1}}\right)-\frac{(1-D)^{2}}{L_{i n} C_{1}}
\end{array}\right]\left[\begin{array}{ccc}
\frac{1}{L_{i n}} & \frac{V_{C 1}+V_{C 2}}{L_{i n}} & \frac{V_{C 2}-V_{C 1}}{2 L_{i n}} \\
0 & \frac{I_{L}}{C_{1}} & -\frac{I_{L}}{2 C_{1}} \\
0 & \frac{I_{L}}{C_{2}} & \frac{I_{L}}{2 C_{2}}
\end{array}\right]\left[\begin{array}{c}
\hat{v}_{i n}(s) \\
\hat{d}(s) \\
\Delta \hat{d}(s)
\end{array}\right]
$$

Therefore, the transfer function that links the control $\hat{d}(s)$ to the inductor input current $\hat{i}_{L}(s)$ :

$$
H(s)=\frac{\hat{i}_{L}(s)}{\hat{d}(s)}=\frac{I_{L}\left(C_{1}+C_{2}\right)}{(1-D)\left(C_{1}-C_{2}\right)} \frac{\left(\frac{\frac{C_{1} C_{2}}{C_{1}+C_{2}}}{I_{L}(1-D)} s+\frac{1}{R I_{L}(1-D)}\right)\left(V_{C 1}+V_{C 2}\right)+1}{\frac{L_{i n} \frac{C_{1} C_{2}}{C_{1}-C_{2}}}{(1-D)^{2}} s^{2}+\frac{L_{i n} \frac{C_{1}+C_{2}}{C_{1}-C_{2}}}{R(1-D)^{2}} s+1}
$$

As well as, the transfer function which links the duty cycle error $\Delta \hat{d}(s)$ to the capacitors voltages difference $\hat{v}_{C 2}(s)-\hat{v}_{C 1}(s)$ :

$$
G(s)=\frac{\hat{v}_{C 2}(s)-\hat{v}_{11}(s)}{\Delta \hat{d}(s)}=\frac{1}{2\left(C_{1}-C_{2}\right) s} \frac{\frac{\left(C_{1}-C_{2}\right)\left(V_{C 2}-V_{C 1}\right)}{(1-D)} s-4 I_{L}\left[\frac{L_{i n}\left(C_{1}+C_{2}\right)}{4(1-D)^{2}} s^{2}+\frac{L_{i n}}{R(1-D)^{2}} s+1\right]}{\frac{L_{i n} \frac{C_{1} C_{2}}{C_{1}-C_{2}}}{(1-D)^{2}} s^{2}+\frac{L_{i n} \frac{C_{1}+C_{2}}{C_{1}-C_{2}}}{R(1-D)^{2}} s+1}
$$

Proposed Control Strategy: The control strategy of this new second topology can also be divided in two parts as above: the generator side 3L-SIDO boost converter and the grid side 3L-NPC converter. Through the generator side 3L-SIDO boost converter, the control plan requires two actives switching devices (IGBT's) which the control of one of them permits to regulate the inductor current (inner loop) in the 3L-SIDO boost converter, the reference current $\mathrm{I}_{\mathrm{ref}}$ is given by controlling the difference between the reference speed $\Omega_{\text {ref }}$ and its measured $\Omega_{\text {rmes }}$ (outer loop). The other switch is controlled to fix the voltage balancing across the two input capacitors of (3L-NPC). As well as through the grid side 3L-NPC converter, the control approach consists of two cascaded loops, a fast internal loop current, which adjusts the current active and the reactive of the grid. The second 
external voltage loop controls DC-link voltage to balance well the flow of power in the grid (see Figure 4).

For the control strategy design, it should simplify the two obtained transfer function equations (20) and (21) related to the (3L-SIDO) boost converter in order to make the design of controller easier, we have used the following approximation:

The high frequency approximation occurs once $w$ is sufficiently large $(s=j \omega)$, can be simplified the equation (20) as:

$$
H(s)=\frac{\hat{i}_{L}(s)}{\hat{d}(s)}=\frac{\left(V_{C 1}+V_{C 2}\right)}{L_{i n} s}
$$

The same approximation can be well simplified too the equation (21) as follows:

$$
G(s)=\frac{\hat{v}_{C 2}(s)-\hat{v}_{C 1}(s)}{\Delta \hat{d}(s)}=\frac{-I_{L}\left(C_{1}+C_{2}\right)}{2\left(C_{1} C_{2}\right)} \frac{1}{s}
$$

First active switching device IGBT of 3L-SIDO Boost converter: The first active switching device IGBT of 3L-SIDO Boost converter contains two loops:

One of them for the inner current control loop and the other for outer speed control loop. The power order provides the rotor speed reference $\Omega_{\text {ref. }}$. The reference is compared with the rotor speed $\Omega_{\text {rmes }}$, this is the speed control loop that gives the input dc current reference $\mathrm{I}_{\text {ref }}$ which are necessary to the current control loop. The duty ratio d adjusts the torque output and hence the rotor speed $\Omega_{\text {rmes }}$ that is fed into the speed loop.

$$
T_{e}-T_{m}=J \frac{d \Omega}{d t}+f * \Omega
$$

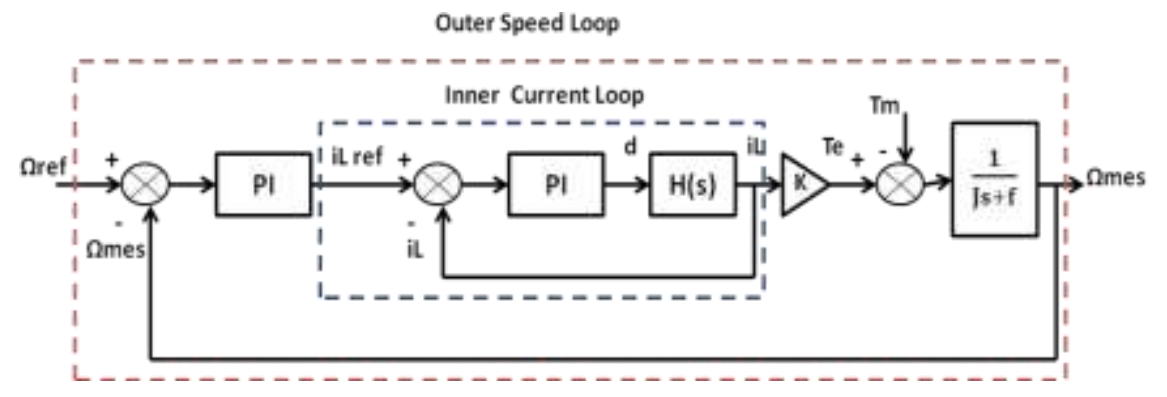

Figure 7. Outer Speed and Inner Current Control Loops

The bandwidth of speed and current loops are taken separately far apart with a slow speed loop and a fast current loop. This can make the design of controller easier.

Inner current control loop: The current loop transfer function $\mathrm{H}(\mathrm{s})$ obtained above equation (22) with parameter values is given as follow:

$$
H(s)=\frac{\hat{i}_{L}(s)}{\hat{d}(s)}=\frac{4.23 * 10^{6}}{s}
$$

The bode plot of $\mathrm{H}(\mathrm{s})$ gives the phase margin $\mathrm{PM}$ equals to $90^{\circ}$ is obtained at crossover frequency $\omega c=4,23 \mathrm{Mrad} / \mathrm{s}$. The PI controller is designed to increase the low frequency gain and reduce the steady state error between the desired and actual inductor currents while maintaining a positive PM at selected crossover frequency.

The open loop transfer function of the current is given by: $H_{O L 1}(s)=H_{P I}(s) * H(s)$

$$
H_{O L 1}(s)=\frac{4.23 * 10^{6} * K_{p}\left(s+\frac{K_{i}}{K_{p}}\right)}{s^{2}}
$$

The phase margin should be $60^{\circ}$ at the gain crossover $\omega_{c}=423 \mathrm{Krad} / \mathrm{s}$ frequency.

From the two conditions of gain and phase at crossover frequency: the system gain is unity and phase angle of the loop equals to $120^{\circ}$, we can obtain the parameters values $\mathrm{K}_{\mathrm{p}}$ and $\mathrm{K}_{\mathrm{i}}$ :

$$
K_{p}=4.21 * 10^{-4} ; \quad K_{i}=102.82
$$


Outer Speed control loop: The outer speed control loop generates the inductor current reference $\mathrm{i}_{\text {Lref }}$ for the inner current control loop as seen in Figure 8. The fast current loop can correct for the current errors quickly. For that reason in the speed loop design, the inner current loop dynamics can be neglected. Its transfer function is not included in the speed loop design.

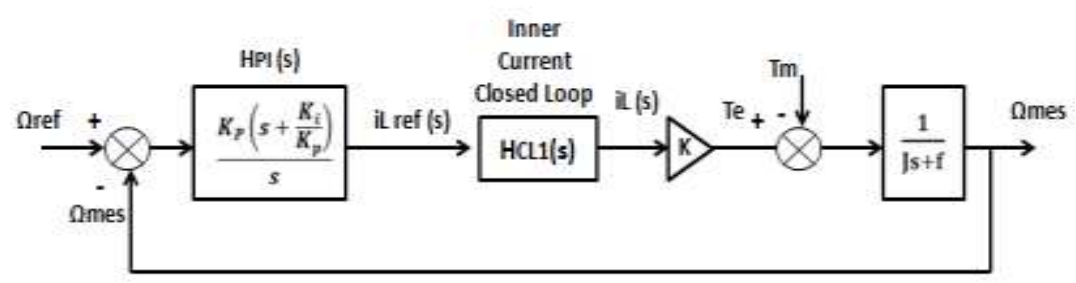

Figure 8. Outer Speed Control Loop Design

The design speed loop gain parameters are well detailed in our previous papers [11], [13] in order to the dynamic system becomes more stable.

Second active switching device IGBT of 3L-SIDO boost converter: The control of the second active switching device IGBT of 3L-SIDO Boost converter resolves the problem of unbalanced voltages across DC-link capacitors of the 3L-NPC inverter. This problem is due to the irregular charging-discharging of the upper-lower DC-link capacitors, and non-identical properties of DC-link capacitors provided by the manufacturer [14], [15]. In order to resolve this problem, a closed loop control strategy is necessary, which reduces the harmonic content as well as maintains voltage stability in the neutral point.

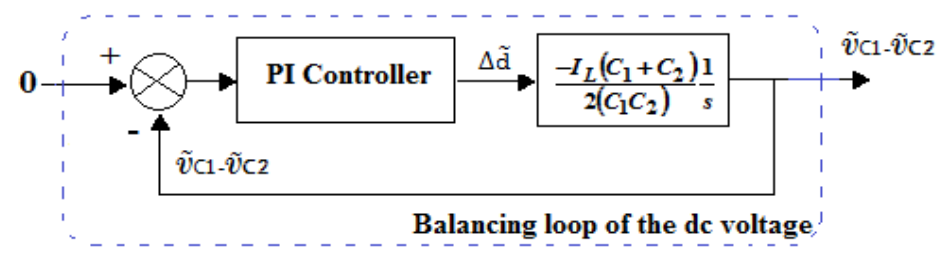

Figure 9. Closed-loop for the Neutral-Point Voltage Control

The closed loop regulator generates error duty cycle $\Delta \hat{d}(s)$ as follows:

$$
H_{P I}(s)=\frac{\Delta \hat{d}(s)}{\hat{v}_{C 2}(s)-\hat{v}_{C 1}(s)}=\frac{K_{p}\left(s+\frac{K_{i}}{K_{p}}\right)}{s}
$$

The duty cycle $\hat{d}_{2}(s)$ controls the NP balancing through the second IGBT switch as follow:

$$
\hat{d}_{2}(s)=\hat{d}_{1}(s)+\Delta \hat{d}(s)
$$

The transfer function of the closed loop for the DC link in the 3L-NPC inverter is given as follows:

$$
\begin{aligned}
& G_{C L}(s)=\frac{G(s) * H_{P I}(s)}{1+G(s) * H_{P I}(s}= \\
& =\frac{-I_{L}\left(C_{1}+C_{2}\right)}{2 C_{1} C_{2}} \frac{K_{p} s+K_{i}}{s^{2}-\frac{I_{L}\left(C_{1}+C_{2}\right) K_{p}}{2 C_{1} C_{2}} s-\frac{I_{L}\left(C_{1}+C_{2}\right) K_{i}}{2 C_{1} C_{2}}}
\end{aligned}
$$

The tuning $\left(\mathrm{K}_{\mathrm{P}} ; \mathrm{K}_{\mathrm{i}}\right)$ parameters of balancing device for controlling the dc voltage is obtained by identification of the equation (30) with the following second order transfer function equation: 


$$
G s o(s)=\frac{2 \xi \omega_{0} s+\omega_{0}^{2}}{s^{2}+2 \xi \omega_{0} s+\omega_{0}^{2}}
$$

Where $\omega_{0}$ is the natural angular frequency, $\xi$ is the damping factor.

From the equations (30) and (31), we can get the values of parameters:

$$
\begin{gathered}
K_{p}=\frac{-4 \xi \omega_{0}\left(C_{1} C_{2}\right)}{I_{L}\left(C_{1}+C_{2}\right)} ; K_{i}=\frac{-2\left(C_{1} C_{2}\right) \omega_{0}{ }^{2}}{I_{L}\left(C_{1}+C_{2}\right)} \\
\text { Where: } \quad \xi=\sqrt{\frac{(\ln P / \pi)^{2}}{1+(\ln P / \pi)^{2}}} \text { and } \omega_{0}=\frac{4.6}{\xi T_{\text {set }}}
\end{gathered}
$$

\section{Simulation Results}

In the purpose of analyzing the dynamic performance and efficiency of the two suggested models and control algorithms for a 7.5MW multi-pole PMSG hydraulic energy conversion system HECS connected to a distribution grid system, digital simulations were executed using matlab/simpower dynamic system simulation software. The sampling time used for the simulation is $2 \mu \mathrm{s}$. The control system of two DC/DC converter $2 \mathrm{~L}-\mathrm{SISO}$ and $3 \mathrm{~L}-\mathrm{SIDO}$ is used to maintain the speed at $1.48 \mathrm{pu}$ corresponding to full power order. The reactive power produced by the HECS is regulated at OMvar.

\subsection{System Response in transient State}

In order to compare the responses of the two chain topologies, the Figure 10 demonstrates the different waves of the two systems response for a constant water flow rate $\mathrm{Q}$ equals to $71 \mathrm{~m} 3 / \mathrm{s}$ corresponding at $7.5 \mathrm{MW}$ of product power hydraulic farm. It should set the simulation stop time to $2 \mathrm{~s}$ and the simulation mode to accelerator in order to attain the steady state of system.

It is observed from the Figure 10 that after a different processing time of dynamic state about $1 \mathrm{~s}$ and $0.3 \mathrm{~s}$, the hydraulic farm system topology 1 and 2 respectively produces a 7.5MW which follows quite well the requested hydraulic power as seen in Figure 10 (c') and (c) respectively, the dc-link voltage is regulated at $1150 \mathrm{~V}$ for the both chains as seen in Figure 10 (b') and (b) respectively and reactive power is preserved at OMVAR as seen in Figure 10 (a') and (a) respectively.

From these results obtained in Figure10, it is presumed that the control system well succeeds to regulate the dc link voltage and active/reactive power at their set points (1150V; 7.5MW; 0MVAR). Also, it can be remarked that the second system using the 3LSIDO DC/DC boost converter in its topology recovers to its steady state after a short time about $0.3 \mathrm{~s}$ and with very low overshoot compared with the first system using the 2L-SISO $\mathrm{DC} / \mathrm{DC}$ boost converter in its topology. 


\subsection{System Response in Steady State}

In this part, we will examine the process of the two chains of Hydraulic Energy Conversion System HECS after reaching the steady state of system as seen in Figure 11 and 12 .
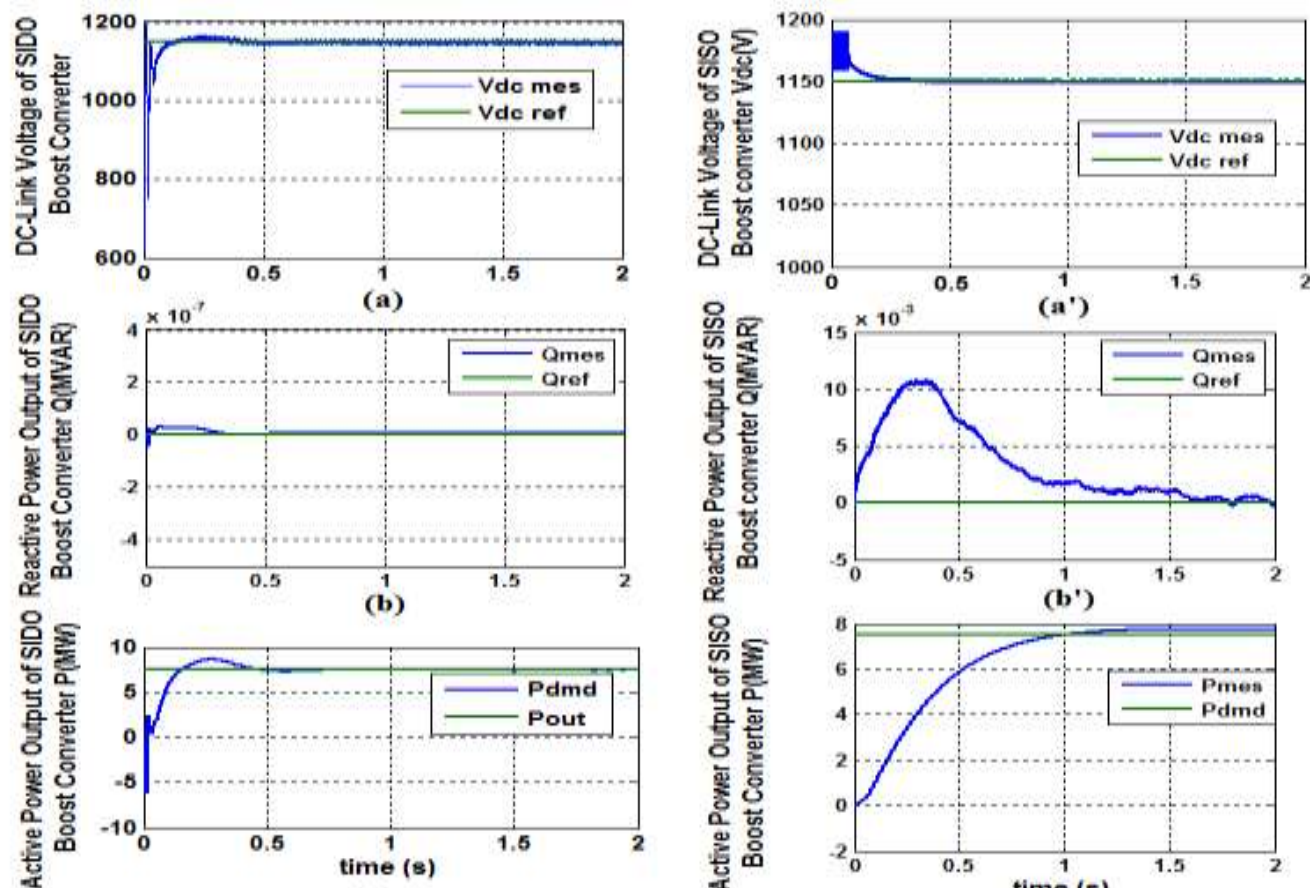

(c)

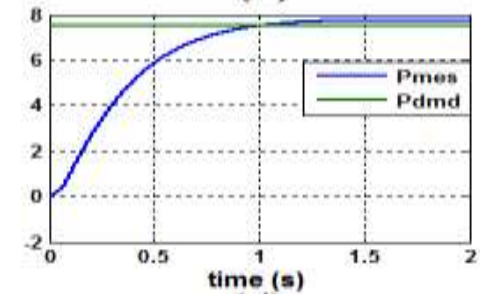

Figure 10. HECS Dynamic Process Response before Reaching Steady State of the Both Chain
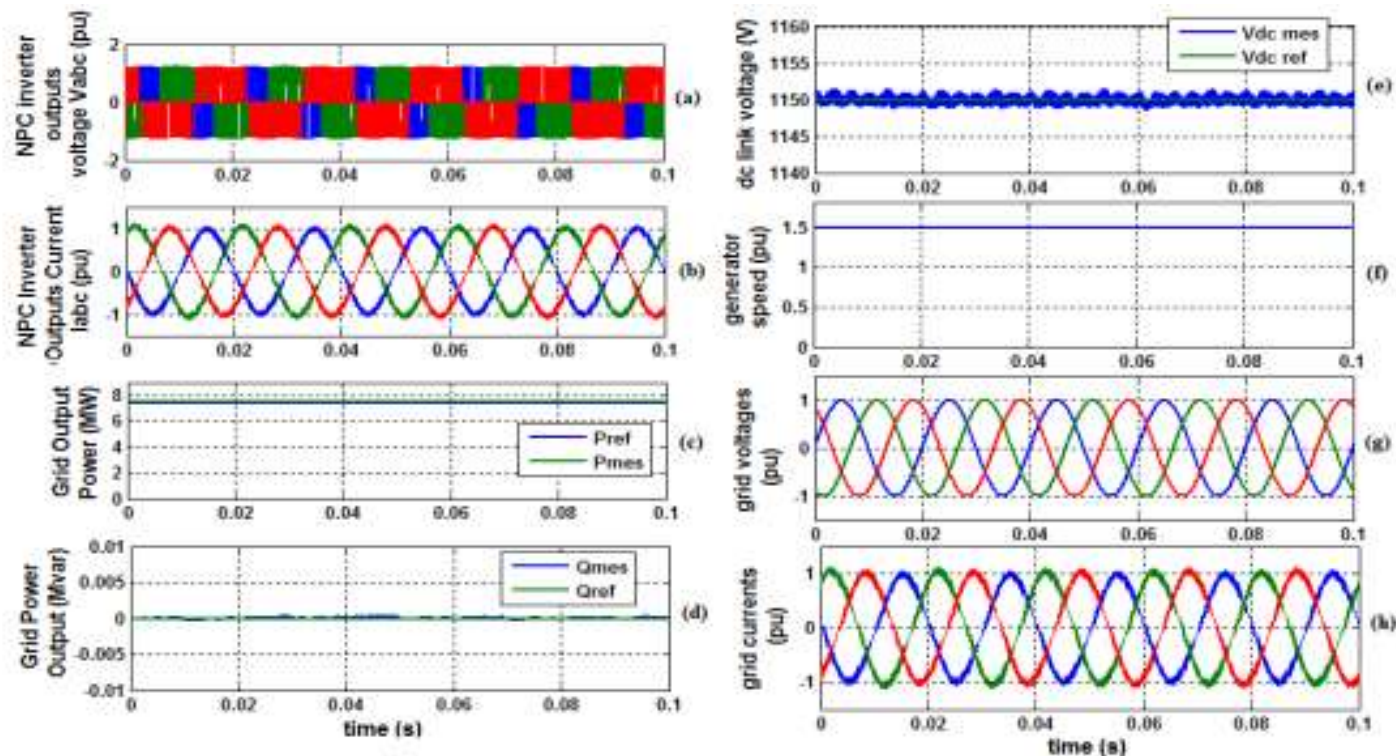

Figure 11. HECS Steady State Process Response for the First Topology with 2L-SISO DC/DC Boost Converter

In this case the simulation models are set-up with all states initialized to start in steadyregime. The delay is due to the time constants of the electromechanical part of the 
hydraulic turbine model and to its quite time for acting the regulators, which it should wait approximately less than $1 \mathrm{~s}$ and $0.3 \mathrm{~s}$ respectively for the first and second topologies as seen in Figure 10. In this circumstance the simulation end time is adjusted to 0.1s and the simulation mode is changed from accelerator to normal as shown in Figure 11 and 12. According to these last figures, it is perceivable that the active power is preserved at its maximum constant value, the reactive power exchanged between the system and the grid remains zero and the voltage in the DC link keeps its value constant for both chains. However the 3L-NPC inverter voltages and currents waveforms for the second topology are approximately sinusoids which facilitate more the filtering part compared with the first topology as seen in Figure11 and 12.
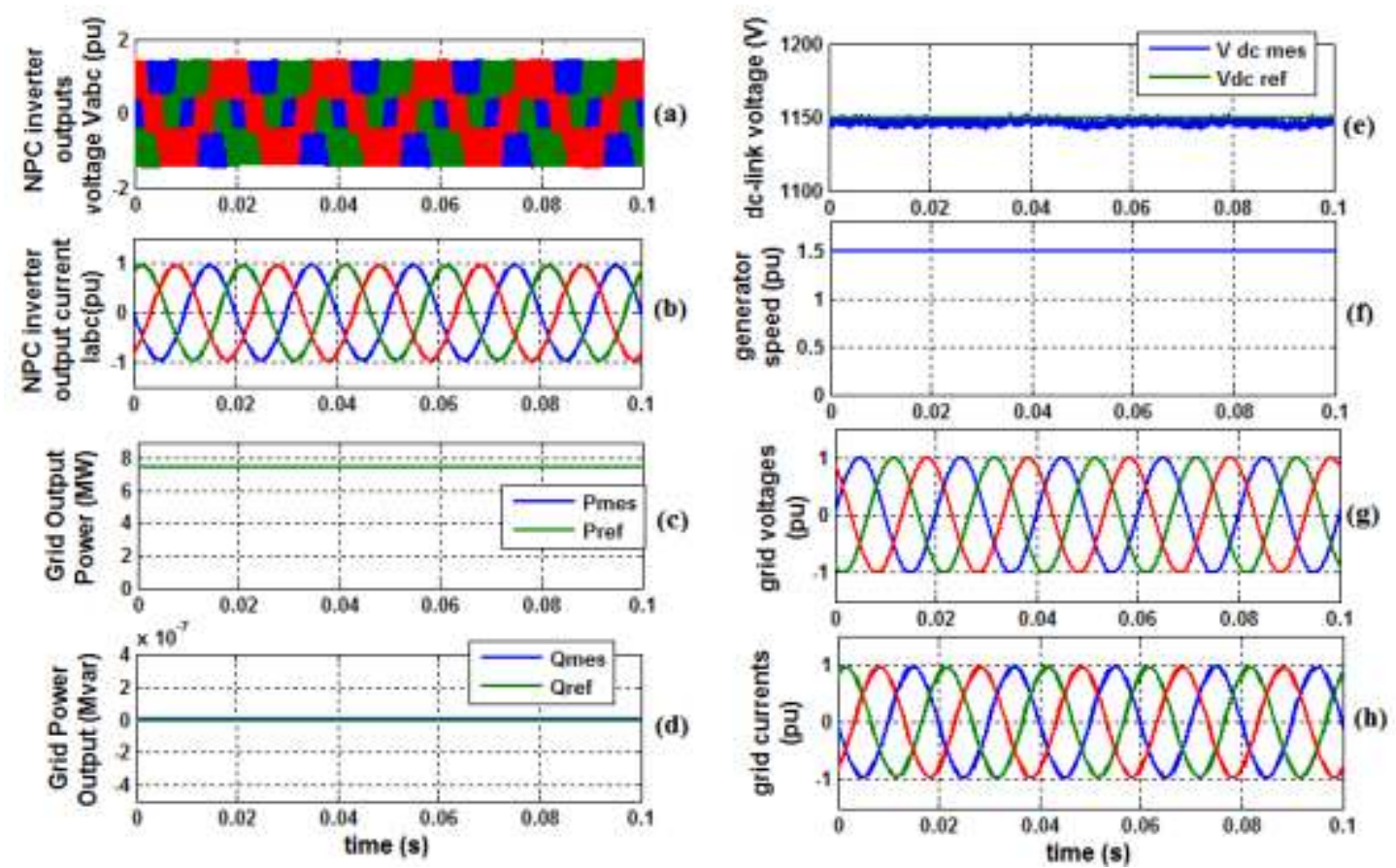

Figure 12. HECS Steady State Process Response for the Second Topology with 3L-SIDO DC/DC Boost Converter

It is deduced that the control algorithm with the second chain topology proves to be accurate in producing the full high power from the hydro station. It's designed with two conveyable duty cycles in accordance with current perturbation in the boost converter dynamics and the voltage balancing across the two capacitors of (3L-NPC) converter. Furthermore, the controllers of this topology work very well and show extremely good dynamic and steady state performance compared with the first topology chain.

\section{Conclusion}

This paper examines in detail the performance of two typical full power converter topologies to select which are the suitable for a direct driven multi-megawatt hydraulic energy conversion system HECS.

Simulation results approve the high effectiveness of the second proposed topology using the 3L-SIDO DC/DC boost converter and its control strategy compared with the other using the 2L-SISO boost converter. This improving system can be increment greatly the settling time to reach quickly the steady state and improve more waveforms outputs of $3 \mathrm{~L}-\mathrm{NPC}$ inverter. Furthermore, the 3L-SIDO DC/DC boost converter has advantage to reduce the voltage stress of the switches which involves low maintenance cost and longer 
life span. However, the problem of 3L-NPC inverter can be solved through the both projected control strategies.

\section{References}

[1] M. Kamil, "Switch Mode power Supply (SMPS) topologies", Part I AN1114A Microchip Technology Inc, (2007), pp. 1-48.

[2] J. Rodrigues and P. Cortes, "Predictive Control of Power Converter and Electrical Drives", John Wily \& Sons, (2012).

[3] Y. Q. Lang, B. Wu and N. Zargari, "Wind power technology - state of the art", IEEE Canadian Review, no.56, (2007), pp.10-17.

[4] Z. Chen, X. Xiao, H. Wang and M. Liu, "Analysis of converter topological structure for direct-drive wind power system with PMSG", Proceedings of the International Conference on Power System Technology POWERCON, Zhejiang, Hangzhou, China, (2010).

[5] S. Seungho, K. Shinil and H. Nyeonkun, "Implementation and control of grid connected AC- DC- AC power converter for variable speed wind energy conversion system", Proceedings of the 18th Annual IEEE Applied Power Electronics, Miami, Florida ,(2003).

[6] F. Blaabjerg and Z. Chen, "Power Electronics for Modern Wind Turbines", 1st ed., Morgan \& Claypool Publishers, (2006).

[7] J. Birk and B. Andresen, "Parallel-connected converters for optimizing efficiency, reliability and grid harmonics in a wind turbine", Proceedings of the 12th European Conference on Power Electronics and. Applications -EPE 2007, Aalborg, Denmark, (2007).

[8] J. Dai, "Current source converters for megawatt wind energy conversion systems", Ryerson University, PhD Dissertation, (2010).

[9] S. Kouro, M. Malinowski, K. Gopakumar, J. Pou, L. G. Franquelo, B. Wu, J. Rodriguez, M. A. Pérez and J. I. Leon, "Recent advances and industrial applications of multilevel converters", IEEE Transactions on Industrial Electronics., vol. 57, no. 8, (2010), pp. 2553 - 2580.

[10] High Energy Production plus Built-in Reliability -the New VENSYS 70/77 Gearless Wind Turbines in the 1.5 MW Class, Proceedings of 2006 European Wind Energy Conference\& Exhibition (EWEC 2006), http://www.ewec2006proceedings.info/ index2.php.

[11] C. Benzazah, L. Lazrak and M. Ait Lafkih, "Modelling and Optimized Control of a 7.5MW Hydraulic Energy Conversion Chain Connected to Distribution System”, European Journal of Scientific Research., vol.146, no. 3, (2017), pp. 310-322.

[12] M.T. Zhang, Yimin Jiang, F.C.Y. Lee and M. M Jovanovic, "Single-phase three-level boost power factor correction circuit", Proceedings of the Tenth Annual Applied Power Electronics Conference and Exposition, Dallas, États-Unis, (1995).

[13] C. Benzazah, L. Lazrak and M. Ait Lafkih, "LCL-filter and PLL Design for Control Three-Level Inverter Neutral-Point-Clamped Connected to Grid for a Multi Megawatt Power Source of Renewable Energy”, European Journal of Scientific Research, vol. 133, no 4, (2015), pp.437-450.

[14] W. Song, X. Feng and K.M. Smedley, "A Carrier-Based PWM Strategy with the Offset Voltage Injection for Single-Phase Three-Level Neutral-Point-Clamped Converters", IEEE Transactions on Power Electronics, vol. 28, no. 3, (2013), pp. 1083-1095.

[15] RM. Tallam, R. Naik and T. Nondahl, "A Carrier-Based PWM Scheme for Neutral-Point Voltage Balancing in Three-Level Inverters," IEEE Transactions on Industry Applications, vol. 41, no.6, (2005), pp. 1734-1743.

\section{Authors}

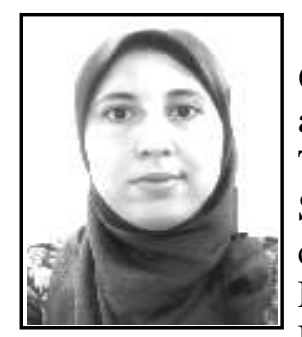

Chirine Benzazah, she was born in Safi, Morocco, on March, 6, 1988. She received her engineer diploma in Electric Systems and Telecommunications from the Faculty of Sciences and Technology, CADI AYYAD University, Morocco in June 2012. She is preparing a $\mathrm{PhD}$ thesis in renewable energy systems control at the Laboratory of Automatic, Energy Conversion and Microelectronics (LACEM), Faculty of Sciences and Technology, University of Sultan Moulay Slimane, Morocco. Her current research interests include power electronics, high-voltage dc, industrial energy efficiency, electrical machines and drives, renewable energy systems control and grid integration. 


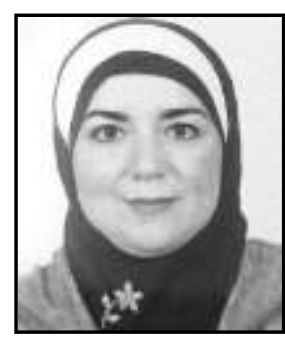

Loubna Lazrak, she was born in Fes, Morocco, on March, 17, 1969. She received her diploma electrical engineering in 1993 and advanced higher studies diploma (D.E.S.A) in 2002 from the National Superior School of Electricity and Mechanics (ENSEM) of Casablanca. She is currently a Professor of electric machines and construction at the Electrical Engineering Department, Faculty of Science and Technology, University of Sultan Moulay Slimane. Her current research interests include control of renewable energy systems and electric machines.

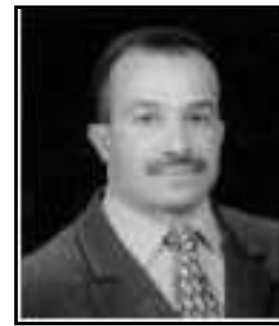

Mustapha Ait Lafkih, he was born in Beni-Mellal, Morocco, on September, 15, 1967. He received his $\mathrm{PhD}$ in Automatic Control from CADI AYYAD University, in 1993. He is currently a Professor of Automatics at the Electrical Engineering Department, Faculty of Sciences and Technology, University of Sultan Moulay Slimane. His current research interests are in adaptive multivariable control. 